\title{
State of stress before and after the 1994 Northridge earthquake
}

\author{
Dapeng Zhao ${ }^{1}$, Hiroo Kanamori ${ }^{2}$, and Douglas Wiens ${ }^{1}$
}

\begin{abstract}
The state of tectonic stress in the epicentral area of the 17 January 1994, Northridge earthquake ( $M w$ 6.7) is investigated by applying a stress inversion method to $P$-wave polarity data from earthquakes in Northridge from July 1981 to January 1994 and from the Northridge aftershocks during January 1994 to December 1995. A 3-D crustal model is used to trace the rays taking off from the hypocenter, which reduced the effects of large structural heterogeneities on the determination of the stress tensor. We found significant temporal changes of stress orientations induced by the Northridge earthquake. The principal pressure $(P)$ axis is oriented $\mathrm{N} 32^{\circ} \mathrm{E}$ from 1981 to June 1992 , and $\mathrm{N} 30^{\circ} \mathrm{E}$ from 28 June 1992 to 16 January 1994, suggesting that the stress field in Northridge was not affected by the 1992 Landers earthquake. During two weeks following the Northridge mainshock, the $P$-axis is oriented $\mathrm{N} 13^{\circ} \mathrm{E}$, which is a significant $\left(17^{\circ}\right)$ change from that before the earthquake (N30 $\left.{ }^{\circ} \mathrm{E}\right)$. Between February 1994 and August 1995 the $P$-axis orientation changes from $\mathrm{N} 18^{\circ} \mathrm{E}$ to $\mathrm{N} 26^{\circ} \mathrm{E}$, and finally ends up at $\mathrm{N} 34^{\circ} \mathrm{E}$ by the end of 1995 , which is close to that before the Northridge earthquake. These results suggest that the stresses rotated coseismically, then rotated more slowly back to their original orientation. The aftershocks caused by the mainshock changed the stress distribution in the crust, which showed up as a regional stress change. The stress recovery appears to have completed within two years after the mainshock, which is very short compared to the time scale of the earthquake cycle.
\end{abstract}

\section{Introduction}

A large earthquake is usually followed by many aftershocks which are distributed in the region surrounding the mainshock. During the mainshock-aftershock sequence spatial and temporal variations of the earthquakegenerating stress field are expected and such changes have been reported for the 1983 Coalinga earthquake (Mw 6.7) [Michael, 1987] and the 1992 Landers earthquake (Mw 7.3) sequences [Hauksson, 1994]. The 17 January 1994 Northridge earthquake (Mw 6.7) has pro-

\footnotetext{
'Department of Earth and Planetary Sciences, Washington University, St. Louis, Missouri

${ }^{2}$ Seismological Laboratory, California Institute of Technology, Pasadena

Copyright 1997 by the American Geophysical Union.

Paper number 97GL00258.

0094-8534/97/97GL-00258\$05.00
}

vided an excellent opportunity for investigating in more detail the possible temporal and spatial stress changes in the epicentral area before and after a major earthquake. The Northridge area is covered by the dense Caltech - USGS Southern California Seismic Network (SCSN). The temporary seismic network deployed following the Northridge mainshock [Steidl et al., 1994] made a more uniform and denser distribution of seismic stations in this area (Figure 1). A detailed 3-D velocity model in the epicentral area [Zhao and Kanamori, 1995] has been available to determine accurate azimuths and take-off angles of the rays at the hypocenter, which results in a more accurate result of the stress tensor since the effects of structural heterogeneities and hypocenter mislocations can be greatly reduced.

\section{Method and Data}

We used the stress inversion method of Horiuchi et al. [1995] to investigate the stress field in Northridge. This method adopts a grid search approach to invert $P$-wave polarity data to estimate the stress tensor and focal mechanisms simultaneously. Rivera and Cisternas [1990] adopted the same approach but a different algorithm. Other stress inversion methods use earthquake focal mechanisms as input data [e.g., Gephart and Forsyth, 1984; Michael, 1987]. The stress inversion using focal mechanisms or $\boldsymbol{P}$-wave polarities as data determines four of the six elements of the stress ten-

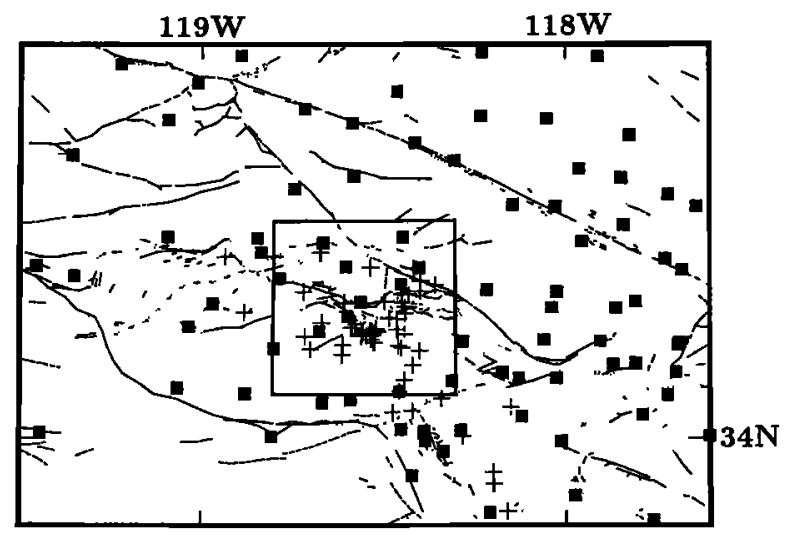

Figure 1. Distribution of the 97 permanent seismic stations (solid squares) of the Caltech-USGS Southern California Seismic Network in the present study area and 59 portable stations (crosses) deployed following the Northridge mainshock. The box shows the Northridge aftershock area (Figure 2). Active faults are shown in thin lines. 
sor. Absolute magnitudes of the stresses cannot be resolved, nor can the isotropic component of the stress tensor without assuming a particular failure criterion. The four remaining elements are given as the orientations of the three principal stresses and the stress ratio, $\phi$, a measure of the relative amplitudes of the stresses. The stress ratio is defined as $\phi=\left(\sigma_{2}-\sigma_{3}\right) /\left(\sigma_{1}-\sigma_{3}\right)$, where $\sigma_{1}, \sigma_{2}$, and $\sigma_{3}$ are the maximum, intermediate, and minimum stresses, respectively.

We used a 3-D velocity model [Zhao and Kanamori, 1995] to calculate azimuths and take-off angles of seismic rays at the hypocenter with the 3-D ray tracer of Zhao et al. [1992]. Horiuchi et al. [1995] uses a single step grid search algorithm to find the four stress parameters in the whole model space, and hence requires an enormous amount of computation when the grid interval is small (e.g., $<6^{\circ}$ ). We have modified their single step algorithm to a multi-step grid search algorithm. We first use a larger grid interval (e.g., $9^{\circ}$ ) to make a coarse search in the whole model space to get a solution, then use a smaller grid interval to search in the vicinity of the solution obtained in the preceding step. This process is iterated until a satisfactory solution is obtained. This multi-step search algorithm greatly reduces the computational load. To estimate the confidence limit of the solution, we used the bootstrap resampling method [Efron and Tibshirani, 1986; Michael, 1987].

We used the $P$-wave polarity data from the earthquakes that occurred in Northridge from 1 July 1981 to 16 January 1994 and from the Northridge aftershocks during 17 January 1994 to 31 December 1995. All the events were recorded by more than 25 stations with $P$ wave polarity data. Note that for some stations there are arrival times but without $P$-wave polarity data. Figure 1 shows the 97 SCSN stations and the 59 portable stations that are used in this study. We relocated all the events using the 3-D crustal model, and the hypocentral locations are accurate to $1-2 \mathrm{~km}$ [Zhao and Kanamori, 1995]. The depth range of the events is from 0.5 to 21 $\mathrm{km} ; 80 \%$ of them fall in the range of $2-17 \mathrm{~km}$.

\section{Results}

We divided the events in Northridge into ten time windows (Figure 2). In each time window, events are selected to obtain a uniform distribution in the aftershock area. We used only those events for which the number of inconsistent polarities was less than $10 \%$ of the data with respect to a fault plane solution. After many tests, we found that this is a reasonable criterion for keeping a large enough number of events and obtaining a stable stress solution. Further finer division of the time window was prohibited by the limited number of events in each window and by the accuracy of the solution we hoped to achieve.

Before looking for temporal variations in the stress field, we first investigated if there are significant spatial variations in the stress field. For each time window, we divided the events into several groups to determine the stress tensor in subareas of the aftershock region. We found that the spatial variations of the stress field are insignificant in each time window; the changes in the stress orientations are generally smaller than $5-6^{\circ}$, within the error range of the solution. If significant spatial stress inhomogeneity exists, the inversion of all the events in one time window would exhibit more than one solution. This, however, did not happen for the inversions for all the ten time windows. There is no systematic change in the pattern of seismicity from window to window for the Northridge aftershocks. This would also tend to cancel any small spatial variation of the stress
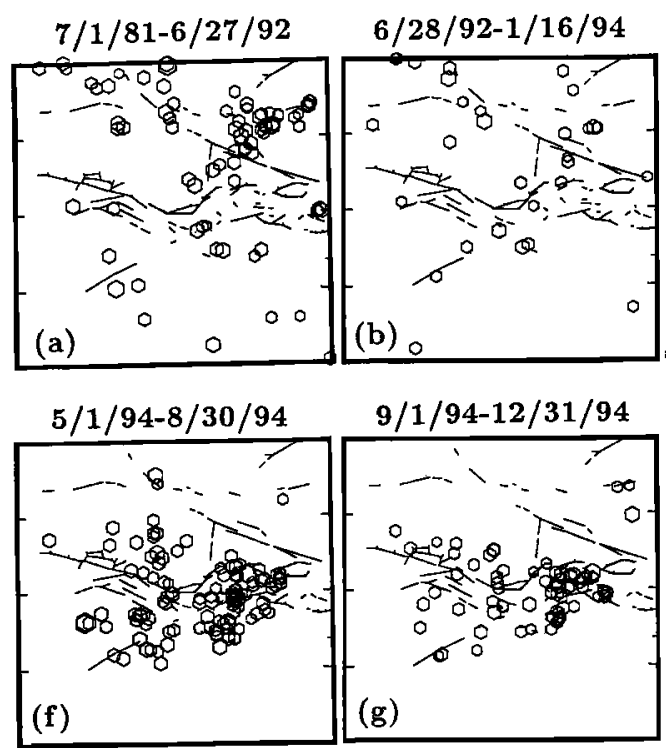
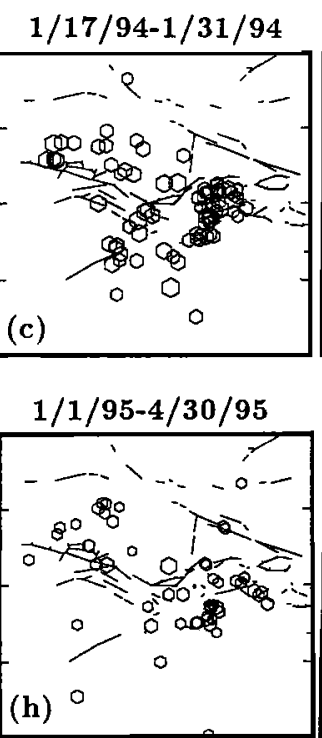

-
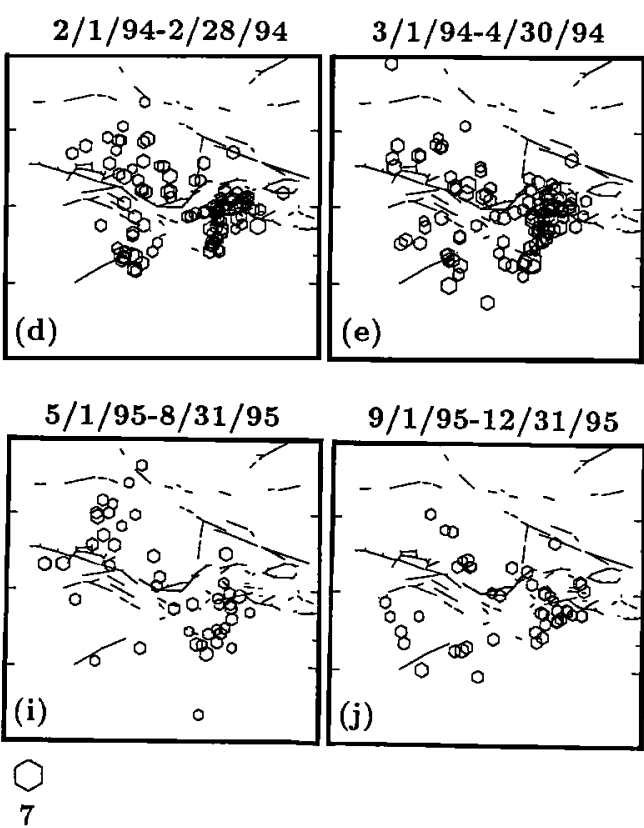

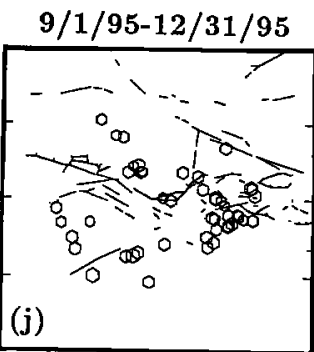

(j)

M O

Figure 2. Epicentral locations of earthquakes (open circles) in the Northridge aftershock area (the box shown in Figure 1) for windows A-J. The time period of each window is shown at the top of each map. The earthquake magnitude scale is shown at the bottom. 


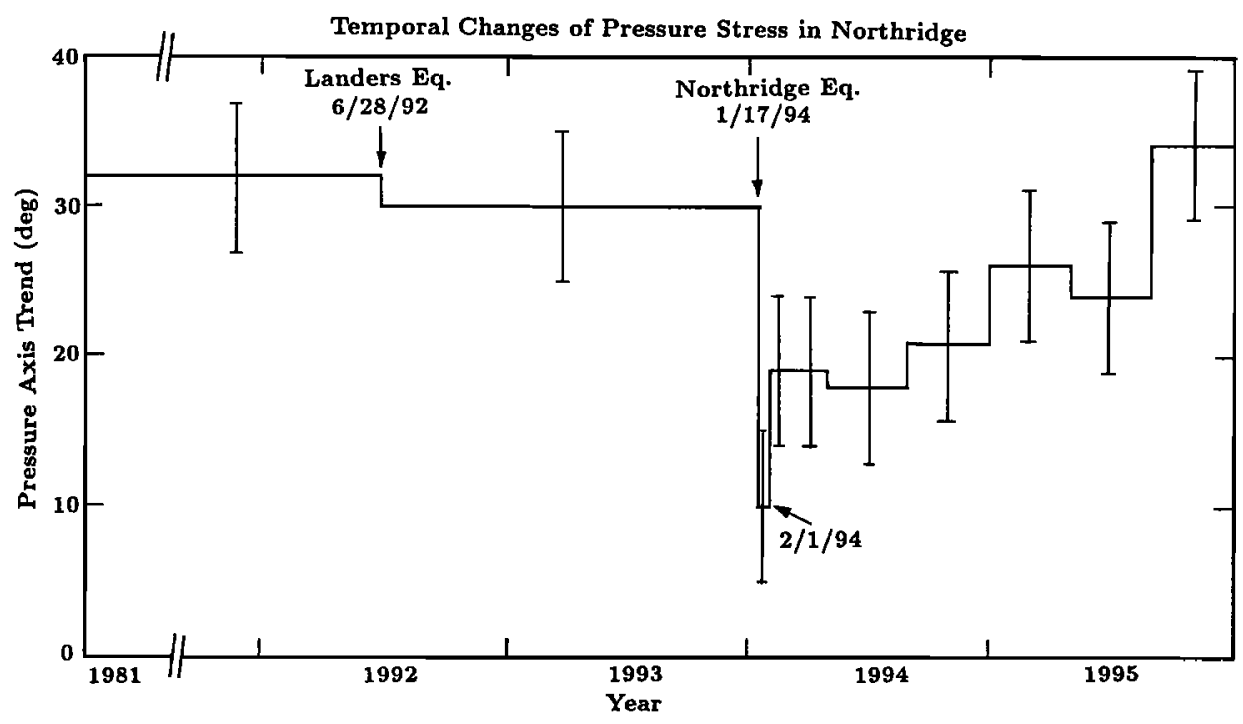

Figure 3. Azimuth of the principal pressure axis versus time in the Northridge area. The vertical bars denote the uncertainty of the azimuth estimates.

field. The background seismicity in windows $A$ and $B$ (Figures 2a and 2b) has a different distribution from that of the Northridge aftershocks (Figures 2c-2j). To examine the effects of this difference, we conducted an inversion by using only those events during 1981-1992 that fall into the exact aftershock area. The inversion gives essentially the same result as that with all the events, though the uncertainty of the solution becomes larger because less data are used. We also computed the average depth and magnitude of the events in each window, and found that there is no significant variation from window to window in either of the quantities. Hence any observed temporal patterns should not be artifacts of stress varying with depth or magnitude.

In the analyses, we have used the 3-D crustal model of Zhao and Kanamori [1995] to calculate azimuths and take-off angles of rays at the hypocenter. We also tried to use a 1-D velocity model that is the average of the 3-D model. We found that the 3-D model resulted in a better stress inversion than the average 1-D model in the sense that $8-10 \%$ more polarity data were explained.

Figure 3 shows the summary of the orientations of the principal pressure $(P)$ axis in Northridge for all the time windows. The stress inversion results for all the three principal stresses in four time windows $(\mathrm{A}, \mathrm{C}, \mathrm{H}$, and $\mathrm{J})$ are shown in Figure 4. As a whole, the $P$-axis is horizontal and oriented to the east of north for all the windows. The stress ratio, $\phi$, is in the range of 0.3-0.5 for all the inversions, indicating that the neutral stress $\left(\sigma_{2}\right)$ is closer in magnitude to the tension stress $\left(\sigma_{3}\right)$ than to the pressure stress $\left(\sigma_{1}\right)$, and the events in Northridge are dominated by thrust faulting mechanisms together with some strike-slip events. These results are in good agreement with the previous studies for the western Transverse Ranges [Gephart and Forsyth, 1984; Hauksson, 1990; Kerkela and Stock, 1996]. The reason for the switch of the tensional $(T)$ and neutral $(N)$ axes for the windows after the Northridge earthquake may be that the two stresses are close to each other in magnitude during those periods $(\phi=0.30-0.35)$. The $T$ and
$N$ axis switch was also found in other regions by the previous studies.

The $P$-axis is oriented $\mathrm{N} 32^{\circ} \mathrm{E}$ from 1 July 1981 to 28 June 1992 , and $N 30^{\circ} \mathrm{E}$ from 28 June 1992 to 17 January 1994. This difference $\left(2^{\circ}\right)$ is insignificant since the error of the stress orientation is estimated to be $5^{\circ}$. This suggests that the stress field in Northridge was almost unaffected by the Landers earthquake. We have conducted three more inversions for the period before the Northridge earthquake by using the events from 1981 to 1986 , events from 1987 to 1992 , and all the events from 1981 to January 1994. All the three inversions gave nearly the same results.

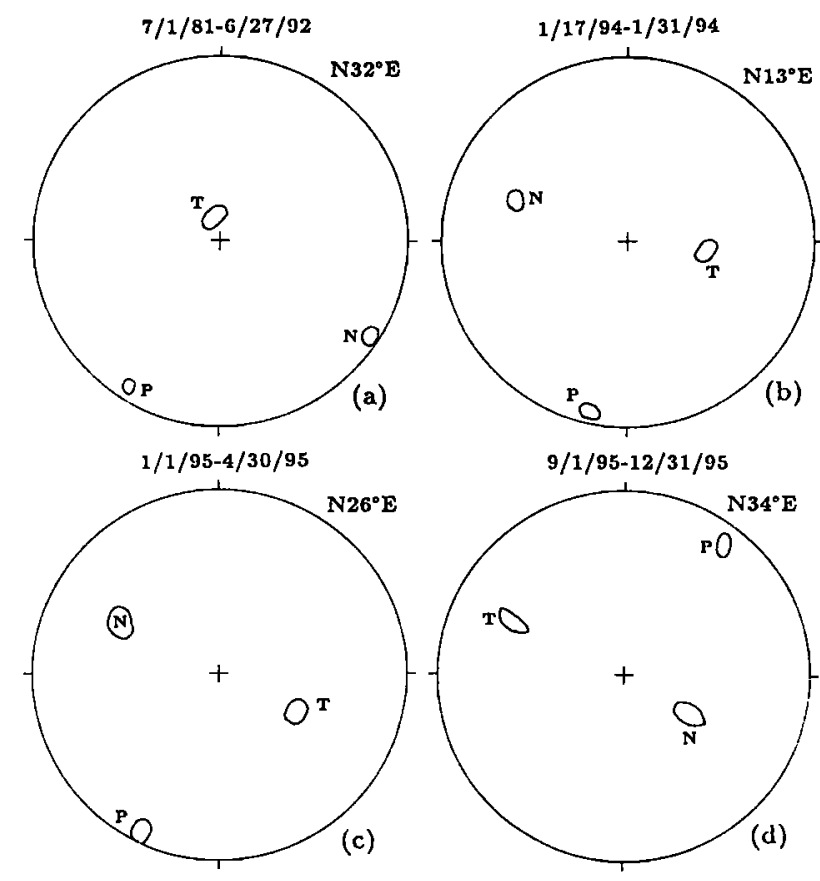

Figure 4. Results of the stress tensor inversions using the earthquakes in the Northridge area in the assigned time period. $\mathrm{P}, \mathrm{T}$, and $\mathrm{N}$ denote principal pressure, tension, and neutral stress axes, respectively. The contours show the uncertainty range of the axes. 
During window $\mathbf{C}$ (two weeks following the Northridge mainshock), the $P$-axis is oriented $\mathrm{N} 13^{\circ} \mathrm{E}$, which is a significant $\left(17^{\circ}\right)$ change from that before the earthquake $\left(\mathrm{N} 30^{\circ} \mathrm{E}\right)$. We have made a number of inversions for this time window by using different subsets of the data; all the inversions gave the same result. Between February 1994 and August 1995 the $P$-axis orientation changes from $\mathrm{N} 18^{\circ} \mathrm{E}$ to $\mathrm{N} 26^{\circ} \mathrm{E}$, and finally ends up at $\mathrm{N} 34^{\circ} \mathrm{E}$ by the end of 1995 (window J), which is close to that before the Northridge earthquake.

\section{Discussion}

Michael [1987] and Hauksson [1994] found similar temporal stress rotations of comparable amount, $15^{\circ}$ for the 1983 Coalinga, and $13^{\circ}-14^{\circ}$ for the 1992 Landers earthquake sequences. Whitcomb et al. [1973] suggested that a change in the stress field of the San Fernando aftershock zone occurred 13 days after the mainshock, on the basis of changes in focal mechanisms. The stress inversion by Gephart and Forsyth [1984], however, did not support such a change, probably because the 20 aftershocks they used were not sufficient to distinguish such a temporal change in the stress field.

These stress change results suggest that the stresses rotated coseismically, then rotated more slowly back to their original orientation. The aftershocks caused by the mainshock changed the stress distribution in the crust, which showed up as a regional change in the stress. As the rate of seismicity decays, so does the stress anomaly. The decay of the stress anomaly is fast at first and then slows down [Michael, 1987]. This is consistent with the suggestions of Benioff [1951] that the existence of aftershocks is related to a stress anomaly that dies away due to viscoelastic creep. The stress rotation might imply the existence of inelastic processes in the rupture zone, e.g., fluids [Johnson and McEvilly, 1995; Zhao et al., 1996]. The theory of Benioff [1951] only shows a change in stress magnitudes, not a rotation of the principal axes as observed during the Coalinga, Landers, and Northridge sequences. However, a rotation of the stress axes and a change in stress magnitudes can be associated phenomena when the stress regime changes. It has been reported that stress changes of up to several bars in magnitude were induced by the Landers and Northridge earthquakes, and most of the aftershocks occurred in areas with raised stress [e.g., Stein et al., 1992, 1994].

The stress recovery appears to have completed within two years after the mainshock. Repeat time of the Northridge earthquake is generally considered to be hundreds to thousands years. Hence the stress directions return to normal very quickly compared to the time scale of the earthquake cycle.

Acknowledgments. We used the data prepared by the Data Center of the Southern California Earthquake Center. We thank S. Horiuchi for providing his original computer program. A. Michael, D. Christensen, and an anonymous referee provided thoughtful reviews, which improved the manuscript. This work was supported by the grants from the National Science Foundation (EAR-9526810) and the U.S. Geological Survey (USGS-SC-7196) to D. Zhao.

\section{References}

Benioff, H., Earthquakes and rock creep, part I, Creep characteristics of rocks and the origin of aftershocks, Bull. Seismol. Soc. Am., 41, 31-62, 1951.

Efron, B., and R. Tibshirani, Bootstrap methods for standard errors, confidence intervals, and other measures of statistical accuracy, Stat. Sci., 1, 54-77, 1986.

Gephart, J., and D. Forsyth, Am improved method for determining the regional stress tensor using earthquake focal mechanism data: Application to the San Fernando earthquake sequence, J. Geophys. Res., 89, 9305-9320, 1984.

Hauksson, E., Earthquakes, faulting, and stress in the Los Angeles Basin, J. Geophys. Res., 95, 15,365-15,394, 1990.

Hauksson, E., State of stress from focal mechanisms before and after the 1992 Landers earthquake sequence, Bull. Seismol. Soc. Am., 84, 917-934, 1994.

Horiuchi, S., G. Rocco, and A. Hasegawa, Discrimination of fault planes from auxiliary planes based on simultaneous determination of stress tensor and a large number of fault plane solutions, J. Geophys. Res., 100, 8327-8338, 1995.

Johnson, P., and T. McEvilly, Parkfield seismicity: Fluid driven? J. Geophys. Res., 100, 12,937-12,950, 1995.

Kerkela, S., and J. Stock, Compression directions north of the San Fernando Valley determined from borehole breakouts, Geophys. Res. Lett., 23, 3365-3368, 1996.

Michael, A. J., Stress rotation during the Coalinga aftershock sequence, J. Geophys. Res., 92, 7963-7979, 1987.

Rivera, L. and A. Cisternas, Stress tensor and fault plane solutions for a population of earthquakes, Bull. Seismol. Soc. Am., 80, 600-614, 1990.

Steidl, J., and SCEC/USGS staffs, SCEC portable deployment following the 1994 Northridge earthquake, Seismol Res. Lett., Northridge Supplement 65, pp. 1, 1994.

Stein, R., G. King, and J. Lin, Change in failure stress on the San Andreas and surrounding faults caused by the $1992 \mathrm{M}=7.4$ Landers earthquake, Science, 258, 1328-1332, 1992.

Stein, R., G. King, and J. Lin, Stress triggering of the 1994 $M=6.7$ Northridge, California earthquake by its predecessors, Science, 265, 1432-1435, 1994.

Whitcomb, J., C. Allen, J. Garmany, and J. Hileman, San Fernando earthquake series, 1971: Focal mechanisms and tectonics, Rev. Geophys., 11, 693-730, 1973.

Zhao, D., and H. Kanamori, The 1994 Northridge earthquake: 3-D crustal structure in the rupture zone and its relation to the aftershock locations and mechanisms, Geophys. Res. Lett., 22, 763-766, 1995.

Zhao, D., A. Hasegawa, and S. Horiuchi, Tomographic imaging of $P$ and $S$ wave velocity structure beneath northeastern Japan, J. Geophys. Res., 97, 19,909-19,928, 1992.

Zhao, D., H. Kanamori, H. Negishi, and D. Wiens, Tomography of the source area of the 1995 Kobe earthquake: Evidence for fluids at the hypocenter? Science, 274, 1891$1894,1996$.

D. Zhao and D. Wiens, Department of Earth and Planetary Sciences, Washington University, St. Louis, MO 63130-4899. (E-mail: dapeng@izu.wustl.edu)

H. Kanamori, Seismological Laboratory 252-21, California Institute of Technology, Pasadena, CA 91125.

(Received : July 5, 1996; Revised : November 19, 1996; Accepted : January 24, 1997.) 